\title{
FACTSHEET
}

\section{INFECTIOUS MONONUCLEOSIS}

Infectious mononucleosis mostly affects teenagers and young adults. The disease is spread through saliva and causes fever, sore throat, and swollen lymph glands. It usually lasts from one week to several weeks. The most effective preventive measures are hand washing and thorough cleaning of soiled objects.

\section{WHAT IS INFECTIOUS MONONUCLEOSIS?}

Infectious mononucleosis (sometimes called glandular fever) is caused by infection with Epstein-Barr virus (EBV).

\section{WHAT ARE THE SYMPTOMS?}

- Infection with EBV usually causes no or few symptoms in young children.

- Teenagers and adults are more likely to become sick if infected.

- Symptoms include fever, sore throat, swollen lymph glands, tiredness, and feeling generally unwell. The doctor may find swelling of the spleen or liver.

- The illness usually lasts between one week and several weeks. A small proportion of people can be sick for months.

- Most people make a complete recovery.

- Once infected, the virus remains in the body for life.

\section{HOW IS IT SPREAD?}

- Infectious mononucleosis is spread from person to person through direct contact with saliva.

- It can be spread from people who are sick with the illness or by healthy people who carry and can spread the virus intermittently throughout their life.

- The time from infection to appearance of symptoms ranges from 4 to 6 weeks.

\section{WHO IS AT RISK?}

- Anybody can get infected with EBV. By the time they are adults, most people will have been infected but only a proportion will have had symptoms.

- Rarely, symptoms can recur in people with a poorly functioning immune system.

\section{HOW IS IT PREVENTED?}

Spread of the virus can be prevented through:

- careful hand washing with soap and running water if you have the illness, especially after sneezing and coughing and before touching other people

- avoiding saliva contact (eg kissing) with people who have the infection

- thorough cleaning with soap and water of soiled objects such as the toys of sick children.

\section{HOW IS IT DIAGNOSED?}

A blood test can confirm the diagnosis in a patient who is suspected of having infectious mononucleosis. This includes a blood count and a 'mono spot' test.

\section{HOW IS IT TREATED?}

There is no specific treatment for infectious mononucleosis. Your doctor can advise on the treatment for symptoms such as fever and sore throat. Rest and a balanced diet may be helpful.

\section{WHAT IS THE PUBLIC HEALTH RESPONSE?}

Infectious mononucleosis is not notifiable in NSW. Cases are not excluded from childcare, school or work, but should be advised to rest at home until they feel better and told how to help prevent spread.

For further information please contact your doctor, local public health unit, or community health centre.

September-October 2005 时 